\title{
A RAZÃo PÚBLICA ENQUANTO BEM PÚBLICO: A PRÁTICA POLÍTICA DA JUSTIÇA NAS SOCIEDADES NACIONAIS DEMOCRÁTICAS
}

\author{
Anna Paula Bagetti Zeifert* \\ Emmanuelle de Araujo Malgarim**
}

Resumo: O presente artigo analisa, a partir da teoria rawlsiana de justiça, os preceitos que governam a discussão política razoável, fundamental para o estabelecimento de sociedades cooperativas e bem ordenadas. Para tanto, fundamental compreender a razão pública como um bem público que impõe um certo limite para a própria ideia de justiça, limite esse estabelecido pelos chamados elementos constitucionais essenciais próprios de sociedades democráticas. Afirmamos que é a concepção política de justiça que orienta a razão pública e os valores políticos que nela estão inseridos, norteando a ideia de justiça presente nas próprias relações entre os cidadãos de uma sociedade democrática.

Palavras-chave: Bem Público. Democracia. Justiça. Política. Razão Pública.

\section{THE PUBLIC REASON AS WELL AS PUBLIC: THE POLITICAL PRACTICE OF JUSTICE IN DEMOCRATIC NATIONAL SOCIETIES}

\begin{abstract}
The present article analyzes, from the rawlsian theory of justice, the precepts that govern the reasonable political discussion, fundamental for the establishment of cooperative societies and well ordered. For this reason, it is fundamental to understand public reason as a public good that imposes a certain limit on the very idea of justice, a limit established by the so-called essential constitutional elements of democratic societies. We affirm that it is the political conception of justice that guides the public reason and the political values that are inserted in it, guiding the idea of justice present in the very relations between the citizens of a democratic society.
\end{abstract}

Keywords: Public good. Democracy. Justice. Politics. Public reason.

\section{INTRODUÇÃO}

A razão pública tem como prioridade as questões públicas essenciais e a harmonia das relações na sociedade democrática, as questões relativas aos elementos constitucionais essenciais e de justiça básica, valores que viabilizam o acordo razoável nas sociedades bem ordenadas.

\footnotetext{
* Doutora em Filosofia (PUCRS). Professora do Programa de Pós-Graduação em Direito - Mestrado e Doutorado em Direitos Humanos - e do curso de Graduação em Direito da Unijuí. É integrante do Grupo de Pesquisa Direitos Humanos, Justiça Social e Sustentabilidade (CNPq). anna.paula@unijui.edu.br

*** Doutoranda em Direito (UNIJUI). Advogada. Professora do curso de Graduação em Direito da Unijuí. É integrante do Grupo de Pesquisa Biopolítica e Direitos Humanos (CNPq). malgarim@gmail.com
} 
Com o intuito de criar as bases para uma sociedade democrática justa, cooperativa, fundada no respeito mútuo e na garantia da liberdade e da igualdade de todos os cidadãos, Rawls (1999) revisita a filosofia política a fim de encontrar subsídios para estabelecer um possível alicerce que sirva de suporte para a estrutura básica de um regime democrático.

Isso restringe a sua concepção política de justiça, pois mesmo sendo uma concepção moral, ela é desenvolvida de maneira a atingir especificamente certo regime social, evitando uma concepção moral geral, como fez o utilitarismo e o intuicionismo. $\mathrm{O}$ autor americano pretende fugir de tais concepções e formular uma teoria capaz de combater os referidos modelos.

No entanto, a concepção de justiça política rawlsiana será desafiada a conviver com as mais variadas doutrinas morais abrangentes, forjadas a partir de questões históricas e sociais que marcaram o nascimento do Estado Moderno.

Rawls (2001) esclarece ser prática e não metafísica a concepção de justiça desenvolvida no âmbito da sua justiça como equidade, a intenção é que essa concepção política de justiça sirva como suporte para um acordo razoável entre cidadãos, e não supõe uma única concepção de bem a prevalecer. Para tanto, há a necessidade de que doutrinas morais abrangentes sejam elas religiosas, morais ou filosóficas colaborem ou passem a apoiar o acordo. No entanto, elas não devem ser a base para o consenso entre os cidadãos.

$\mathrm{O}$ acordo é relativo às questões que efetivamente irão garantir a estabilidade da sociedade e de um regime democrático. As doutrinas morais abrangentes e seus valores são relevantes nesse acordo somente quando corroboram com os valores políticos fundamentais. Por isso a importância de discutir a ideia de razão pública, enquanto bem público, e os valores que nela estão inseridos compreendendo o que será parte de um acordo para que uma sociedade justa e igualitária de desenvolva.

Para seu desenvolvimento, o estudo utiliza o método de abordagem hipotéticodedutivo, valendo-se de uma base teórica presente na filosofia política contemporânea capaz de auxiliar na compreensão e na sistematização dos conceitos fundamentais para pensar a justiça a partir do liberalismo igualitário.

\section{UMA CONCEPÇÃO POLÍTICA DE JUSTIÇA PARA SOCIEDADES POLÍ́TICAS}


Rawls (1999) tem como preocupação esclarecer que uma concepção de justiça possua uma justificação a partir de questões práticas da realidade social, não devendo ser concebida como um problema epistemológico ou metafísico. Uma concepção plena (completa) de justiça é o que norteia Rawls e está diretamente ligada a organização da vida em sociedade, suas instituições e os princípios de justiça.

Fica evidente, que o objetivo do autor americano é um acordo possível, livre, que possibilite a reconciliação da sociedade por meio do que ele denominou de public reason, bem como, uma concepção específica de cidadão como pessoas livres e iguais e a aplicação do princípio da tolerância à própria filosofia. Para Rawls (1999), a aplicação do princípio, seria um "método de esquiva", uma forma de amenizar ou melhorar, moderar incompatibilidades existentes entre várias formas de pensamento e doutrinas morais existentes no interior de uma sociedade, que produzem muitas visões políticas por vezes concorrentes.

Ajustes seriam fundamentais para que o respeito mútuo e as bases para uma sociedade justa guiada pela cooperação entre cidadãos livres e iguais se solidificassem. Uma serie de ideias são elencadas pelo autor americano com a intenção de demonstrar que efetivamente a sua justiça como equidade deve ser compreendida como uma concepção política de justiça e que só seria possível em uma "sociedade cooperativa" de cidadãos livres e iguais. No caso da cooperação, essa seria orientada por procedimentos e normas/regras reconhecidos publicamente, aceitos por todos que se dispõe a cooperar, visto que a cooperação requer reciprocidade entre todos os agentes envolvidos, de maneira que todos se sintam responsáveis e percebam que a vantagem obtida é racional. (RAWLS, 1985)

Importa considerar que a ideia de pessoa, na concepção ralwsiana, se distancia das noções formuladas pela ciência natural ou na teoria social. A sua concepção é política e requer o estabelecimento de duas capacidades essenciais: senso de justiça e uma concepção de bem, respectivamente, a configuração de indivíduos razoáveis e racionais. Para tanto, Rawls (1992, p. 41) observa que sua teoria tem um objetivo muito claro desde o princípio e que estaria sendo reforçado pela idealização de uma concepção de pessoa.

\footnotetext{
${ }^{1}$ Compreende o autor, que "a teoria de Rawls vai apresentar-se como uma teoria deontológica da justiça distributiva. Ela irá mostrar-se incompatível com todo princípio sacrificial, sem cair na censura de inveja nem nas dificuldades da meritocracia, mas tendo em conta as exigências modernas da eficácia, da igualdade e do pluralismo das finalidades." (BOYER, 2001, p. 49-50, grifo do autor)
} 
As capacidades morais requeridas para tal concepção e a noção de indivíduos livres e iguais são "ideias básicas intuitivas presumidamente implícitas na cultura política de uma sociedade democrática."2 A questão da justiça política, seria dependente de tais ideias intuitivas básicas para que fosse possível a construção de uma sociedade igualitária.

Diante do exposto, a justiça como equidade que visa fundar uma sociedade mais justa considerando a sua concepção de justiça política, está muito além de ser considerada uma doutrina moral abrangente nos moldes do liberalismo. Quando formuladas no seio de uma democracia razoavelmente justa, as ideias intuitivas básicas serão endossadas pelas mais variadas doutrinas morais abrangentes existentes no seu interior. É tarefa da proposta de justiça rawlsiana reconhecer os pontos de convergência possíveis para o consenso, identificando "as ideias básicas compartilháveis que, elaboradas numa concepção política de justiça revelou-se suficiente para garantir um regime constitucional justo.” (RAWLS, 1993, p. 53)

Seria interessante retornarmos a um dos pontos da teoria rawlsiana que é de fundamental importância para o argumento desse trabalho, qual seja: como justificar publicamente uma concepção de justiça? Referida preocupação é pertinente no momento em que a aceitação de uma concepção de justiça que se diz política, pública, servirá de base para a aceitação, também, dos princípios de justiça concebidos no âmbito dessa sociedade. Objetivamente, Rawls (1993) acrescenta a necessidade dessa concepção política de justiça se desenvolver no interior de uma sociedade democrática, endossada por todas as doutrinas morais abrangentes existentes no interior e por cidadãos livres e iguais.

Porém, o autor americano precisa ir mais a fundo para que essa proposta de justiça como equidade se torne parte da vida pública. Necessita tornar forte o sentido da justiça em cada sujeito a fim de que no embate entre uma concepção de bem não razoável, a justiça, ou melhor, os princípios de justiça, prevaleçam e passem a servir de guia para a instauração da justiça social. Nas palavras de Lovett (2013, p. 117, grifo do autor), "não é suficiente que os cidadãos tenham meramente um desejo de promover a justiça se esse desejo não for forte o bastante para regular os seus planos de vida."

\footnotetext{
${ }^{2}$ Conforme Rawls (1992, p. 41) “[...] a justiça como equidade elabora em termos de concepções idealizadas certas ideias intuitivas fundamentais, como as de pessoas livres e iguais, de sociedade bem ordenada e do papel público de uma concepção de justiça política; penso ainda que ela conecta essas ideias intuitivas fundamentais com a ideia intuitiva, ainda mais fundamental e abrangente, da sociedade enquanto sistema equitativo de cooperação ao longo do tempo e uma geração à outra. Direitos, deveres e objetivos são apenas elementos dessas concepções idealizadas."
} 
O senso de justiça em cada cidadão deve ser necessariamente sólido, resistir a qualquer obstáculo ou afronte, garantindo o projeto social adequado no interior de uma sociedade que tem como objetivo ser bem ordenada. Esse senso de justiça forte viabiliza a estabilidade e, consequentemente, a justiça como equidade enquanto teoria que prima pela cooperação, fundamento da justiça política rawlsiana.

Como essas possibilidades de estabilidade social foram trabalhadas em A Theory, observamos a influência kantiana na teoria rawlsiana ${ }^{3}$, no entanto, com o passar do tempo, Rawls revisa este modelo de estabilidade por entender que o mesmo poderia induzir ao erro quem pretendesse utilizá-lo como forma de medir o grau de solidez de uma sociedade com relação à justiça social. Outra situação que deve ser considerada é o fato de que a concepção do bem formulada e passada de geração para geração pode facilmente ser uma doutrina moral que no interior se apresenta inteiramente contraditória com a realidade social.

Por tais razões é que Rawls, nas reformulações, opta por adotar as expressões "consenso sobreposto" e "doutrinas morais abrangentes" como forma de melhor explicar e embasar a sua teoria da justiça como equidade, bem como uma noção inteiramente nova de estabilidade tendo como referência a ideia de pluralismo razoável. ${ }^{4}$

\section{A RAZÃO PÚBLICA ENQUANTO BEM PÚBLICO: UMA CONCEPÇÃO DE JUSTIÇA COMPARTILHADA}

\footnotetext{
${ }^{3}$ Em sua obra Ricoeur (1995, p. 40, grifo do autor), passa a questionar os caminhos escolhidos por Rawls para desenvolver a sua teoria e a sua própria ideia de justiça. Segundo o autor, existiriam duas razões para sua escolha, a primeira é que Rawls "[...] situa-se mais na descendência de Kant que de Aristóteles." Para Aristóteles a teoria da justiça deveria ser compreendida ...] como uma virtude particular a saber, a justiça distributiva e corretiva tira o seu sentido, como todas as outras virtudes, do quadro teleológico do pensamento que a coloca em relação com o bem, pelo menos tal como é compreendido pelos seres humanos;" Já em Kant, diferente de Aristóteles, "verifica-se uma inversão de prioridade em benefício do que é justo e em detrimento do que é bom, de tal modo que a justiça ganha sentido num quadro deontológico de pensamento." Já a segunda razão, visa esclarecer que "enquanto em Kant a ideia de justiça aplica-se antes de mais às relações de pessoa a pessoa, com Rawls a justiça aplica-se prioritariamente às instituições - é a virtude por excelência das instituições - e somente a título secundário aos indivíduos e aos estadosnação considerados como indivíduos no palco da história."

${ }^{4}$ Audard (2006. p. 11), "A Teoria da justiça como equidade procuraria reconciliar ou pacificar as sociedade pluralistas apresentando os princípios de justiça aos quais os cidadãos devem se submeter. Esses princípios seriam puramente 'políticos' ou seja, não colocariam em questão suas crenças pessoais. Não tendo nenhuma pretensão à verdade, esses princípios não poderiam entrar em choque com a fé religiosa, as opiniões morais e as filiações dos cidadãos."
} 
Os valores que norteiam a ideia de justiça estão presentes como requisitos fundamentais para a cooperação na sociedade bem ordenada, são de suma importância para o estabelecimento dos elementos constitucionais essenciais. Relevante, nesse cenário, os preceitos que governam a discussão política razoável, que, para Rawls (2000), deve ser pensado a partir da noção de razão pública. A razão pública é a forma pela qual a sociedade política articula seus planos, suas prioridades nas tomadas de decisões, os procedimentos utilizados e a capacidade de institui-los. Seria integrante dessa sociedade política "todo o agente razoável e racional, quer seja um indivíduo, uma família, uma associação ou mesmo uma confederação de sociedades políticas." 5

Em seu conteúdo, a razão pública busca apresentar as ideias e princípios fundamentais que serão objeto de interesse de todos os cidadãos em uma sociedade democrática. ${ }^{6}$ A razão pública, segundo requer a concepção política de justiça rawlsiana, deve ser compartilhada por todos os cidadãos (livres e iguais, razoáveis e racionais), pois expressa a razão da sociedade democrática formada por cidadãos que possuem uma cidadania igual. "Seu objeto é o bem público", aquilo que efetivamente interessa para a sociedade como “justiça fundamental”. É um bem público, impondo certo limite para a própria ideia de justiça. É possível dizer que, nesse contexto, há um limite à razão pública estabelecido pelos chamados elementos constitucionais essenciais, conforme descreve Rawls (2000, p. 262).

A preocupação da razão pública é com questões públicas essenciais e com a harmonia das relações na sociedade democrática. ${ }^{7}$ Seria objeto da razão pública as questões relativas aos elementos constitucionais essenciais e de justiça básica, valores que viabilizam o acordo $^{8}$ na sociedade bem ordenada. Dentre as questões públicas que não seriam objeto de análise pela razão pública, estariam: o direito de voto, tolerância à determinada religião, igualdade equitativa de oportunidades, direito de propriedade,

\footnotetext{
${ }^{5}$ Rawls (2000. p. 261) É necessário esclarecer que para Rawls nem todas as razões são públicas. Existem razões não públicas ligadas às "igrejas, universidades e muitas outras associações da sociedade civil."

${ }^{6}$ Conforme destaca Cohen (1998) os cidadãos em uma democracia compartilham de um conjunto de razões que são apropriadas para todos. Além de regular a concentração de poder, as decisões coletivas demonstram a soma das intenções da maioria. Há, nesse ponto, uma concordância entre Rawls e Cohen, uma vez que ambos entendem que essa forma de organização em uma sociedade democrática permite diminuir os impasses possíveis diante da existência de um conjunto de doutrinas morais abrangentes. A busca por um ponto comum se faz necessário para estabilizar e definir termos razoáveis de cooperação.

7. Para Freeman (2003), a public reason está fundamentada no domínio do público e isso exige uma unidade em torno daquilo que é essencial para a sociedade como um todo e que poderia ser objeto de consenso.

${ }^{8}$ Como explicita o autor, “[...] numa sociedade democrática, a razão pública é a razão de cidadãos iguais que, enquanto corpo coletivo, exercem um poder político final e coercitivo uns sobre os outros ao promulgar leis e emendar sua constituição." (RAWLS, 2000. p. 263)
}

Rev. De Teorias Da Justiça, Da Decisão E Da Argumentação Jurídica| e-ISSN: 2525-9830| Goiânia| v. 5 | n. 1 | 
legislação fiscal, proteção ao meio ambiente e manutenção de parques nacionais e museus. Tais questões, por vezes, podem ser consideradas essenciais para a vida em sociedade, mas, no entanto, há de se delimitar a extensão da razão pública às questões mais fundamentais. (RAWLS, 2000)

Esses limites à avaliação do que seria objeto ou não de análise da razão pública, não significa o seu fechamento total para outras questões que, também, são relevantes para a sociedade. O que Rawls denomina de "cultura de fundo" da sociedade política, de certa forma estará sempre presente no fórum público da razão. "Discussões e reflexões pessoais sobre questões políticas", bem como as análises proferidas "por parte de membros de associações como as igrejas e universidades", ou seja, "considerações religiosas, filosóficas e morais de muitos tipos, desempenham um papel” na sociedade, na esfera pública. Cidadãos continuam, porém, a desempenhar o principal papel no fórum público da razão, quando argumentam politicamente sobre os interesses que envolvem a justiça política e os elementos fundamentais. No fórum público da razão, além dos cidadãos, também estarão presentes os "membros dos partidos políticos" e "candidatos em campanha", e todos devem ter presente o ideal que norteia a razão pública, qual seja, o bem público. ${ }^{9}$

Nesse contexto, fica evidenciado o quão importante são os valores ${ }^{10}$ presentes em uma sociedade democrática; valores esses que estarão em jogo quando se estabelecer as diretrizes para uma sociedade bem ordenada. Por isso a necessidade de que, no momento do consenso sobreposto, tais valores sejam considerados a ponto de fazer com que as várias concepções de justiça presentes, em razão das doutrinas morais abrangentes e razoáveis, concordem e endossem o projeto de justiça política. Como aduz Rawls (2000, p. 267),

\footnotetext{
9. Para tanto, “[...] o ideal de razão pública não só governa o discurso público das eleições, quando aquelas questões fundamentais estão em jogo, como também a forma pela qual os cidadãos devem escolher no que votar a respeito dessas questões. Caso contrário, o discurso público corre o risco de ser hipócrita: os cidadãos falam uns com os outros de uma forma e votam de outra." (RAWLS, 2000. p. 264)

${ }^{10}$ Audard (2006, p. 126) também fala num conjunto de valores presentes na sociedade, no entanto esses valores fariam parte de uma ética pública "[...] que permitiriam legitimar as normas coletivas às quais devemos nos submeter enquanto cidadãos e, portanto, obedecer sem a intervenção da força. Sem homogeneidade cultural e sem pacificação orgânica, fundadas sobre as crenças e convicções morais dos cidadãos, as instituições democráticas perderiam toda a autoridade e seriam condenadas a perecer, como mostra claramente a derivação inquietante em direção a uma "democracia de opinião."
} 
A união do dever de civilidade com os grandes valores do político produz o ideal de cidadãos governando a si mesmos, de um modo que cada qual acredita que seria razoável esperar que os outros aceitem; e esse ideal, por sua vez, é sustentado pelas doutrinas abrangentes que pessoas razoáveis defendem. Os cidadãos defendem o ideal da razão pública não em consequência de uma barganha política, como num modus vivendi, mas em virtude de suas próprias doutrinas razoáveis.

O autor americano afirma, ainda, uma espécie de paradoxo nesse ponto da sua argumentação. Ele questiona como os cidadãos apoiariam uma concepção pública de justiça sem considerar a realidade na qual estão inseridos. Inicialmente, Rawls (2000) busca sustentação para sua resposta ao invocar o princípio da legitimidade liberal. Tal princípio estaria vinculado a duas questões fundamentais para os cidadãos em uma sociedade democrática. A primeira delas diz respeito a nascer e por toda a vida viver em uma sociedade, a relação entre os indivíduos e, a segunda, o poder político, que é público e fruto da união coletiva dos cidadãos. Quando, porém, o consenso sobreposto passa a sustentar a concepção política para uma sociedade democrática e bem ordenada, e isso reforça o elo de ligação entre os cidadãos que professam as mais diversas doutrinas morais abrangentes e razoáveis, o paradoxo que se impõe inicialmente é superado.

Importa, nesse momento, a argumentação rawlsiana em torno do conteúdo da razão pública para esclarecermos a sua importância na construção de uma sociedade justa e igualitária. Essa razão pública irá se estabelecer tendo como base uma concepção de justiça política aplicada à "estrutura básica da sociedade e suas principais instituições políticas, sociais e econômicas," de maneira a articular um sistema de cooperação que independe de doutrinas morais abrangentes, mas que considera relevantes as ideias políticas e públicas presentes de forma implícita na cultura democrática de fundo. É essa base que irá receber os princípios de justiça e, a partir deles, criar as diretrizes para o estabelecimento dos valores que irão permear a construção dos elementos constitucionais fundamentais. (RAWLS, 2000, p. 273)

Assim sendo, o conteúdo da razão pública, para Rawls (2000, p. 273), é elaborado a partir da sua proposta de justiça como equidade, mais especificamente pela "concepção política de justiça". Nele estarão presentes "direitos, liberdades e oportunidades fundamentais", visando o benefício de todos os cidadãos, retratando o que fora previamente expresso nos princípios de justiça. São os valores liberais presentes nos regimes democráticos: "igual liberdade política e civil, da igualdade social e da reciprocidade econômica; e acrescentamos ainda os valores do bem comum, assim como 
várias condições necessárias a todos esses valores." Cabe destacar, ainda, que, mesmo havendo a prioridade do justo sobre o bem, o valor bem comum permanece.

A esses valores podemos acrescer os valores da razão pública, que estão ligados a “categorias das diretrizes da indagação pública que tornam essa indagação pública livre e pública." São parte, também, "as virtudes políticas como a razoabilidade e a disposição de respeitar o dever (moral) de civilidade," fundamentais para que a discussão pública seja possível e que tenha como pauta as questões relativas ao político e ao público. Esses valores pressupõem uma concepção de pessoa política (normativa), capaz de ter a virtude do senso de justiça. (RAWLS 2000. p. 274)

A razão pública, assim como os princípios de justiça, aparecem sustentados pelo mesmo alicerce. ${ }^{11}$ A justiça como equidade dará as diretrizes e ambos farão parte do acordo cooperativo travado no interior da sociedade. Todas as ações praticadas devem ser justificadas publicamente garantindo a legitimidade política da justiça, sejam elas relativas à estrutura básica da sociedade ou à promoção de políticas públicas que atinjam todos os cidadãos.

Não seria diferente, quando falamos dos elementos constitucionais essenciais, que, por tratar de valores fundamentais para a estabilização da ordem democrática, requerem a legitimidade política e pública para seu reconhecimento pela sociedade. Também é importante destacar que as crenças gerais e as argumentações presentes no senso comum dos cidadãos farão parte das discussões e servirão como direção das indagações públicas. Conforme Rawls (2000, p. 276-277),

O que importa no ideal de razão pública é que os cidadãos devem conduzir
suas discussões fundamentais dentro daquilo que cada qual considera uma
concepção política de justiça, baseada em valores que se pode razoavelmente
esperar que os outros subscrevam, e cada qual está, de boa-fé, preparado para
defender aquela concepção entendida dessa forma. Isso significa que cada um
de nós deve ter e deve estar preparado para explicar um critério acerca de que
princípios e diretrizes pensamos que se pode razoavelmente esperar que os
outros cidadãos (que também são livres e iguais) subscrevam junto conosco.
Evidentemente, podemos descobrir que, na verdade, há os que não subscrevem
os princípios e diretrizes que nosso critério seleciona. Isso é algo que devemos
esperar. A ideia é que necessitamos ter um critério desse tipo, e só isso já impõe
uma disciplina muito considerável à discussão pública. Não é de qualquer valor
que se pode razoavelmente dizer que passará nesse teste ou que será um valor

${ }^{11}$ Compreende Silveira (2009, p. 69) que "os dois princípios da justiça [...] aparecem como conteúdo da razão pública e isso explica o significado de uma concepção política de justiça que: (i) se aplica exclusivamente à estrutura básica da sociedade, (ii) apresenta uma visão independente de qualquer doutrina abragente e (iii) é elaborada em termos de ideias políticas fundamentais." 
político; e nem todo equilíbrio de valores políticos é razoável. É inevitável e muitas vezes desejável que os cidadãos tenham visões diferentes no que diz respeito à concepção política mais apropriada, pois a cultura política pública está fadada a conter diferentes ideias fundamentais, que podem ser desenvolvidas de formas diferentes. Um debate ordenado entre elas ao longo do tempo é uma forma confiável de descobrir qual é a mais razoável, se alguma o é.

O acordo em torno de questões fundamentais é importante para que uma concepção política de justiça se efetive completamente. Essas questões fundamentais influenciadas por valores políticos que servirão de base para o estabelecimento de elementos constitucionais essenciais e, também, às diretrizes para as noções básicas de justiça social. Tais elementos constitucionais essenciais se expressam de duas formas: "a) especificam a estrutura geral do Estado e do processo político, e os elementos essenciais" (estariam presentes aqui as competências dos três poderes - Executivo, Legislativo e Judiciário), e o processo político considerando a "regra da maioria"; e os "elementos essenciais em b) que se especificam os direitos e liberdades fundamentais e iguais dos cidadãos." Nesse último caso, é importante destacar os direitos e liberdades fundamentais e de igual cidadania, tais como direito de participar da vida política do Estado (voto), "liberdade de consciência, a liberdade de pensamentos e de associação, assim como as garantias do império da lei." Estariam inclusos nesse conteúdo, ainda, “os princípios que regulam as questões básicas de justiça distributiva, como a liberdade de movimento e a igualdade de oportunidades, as desigualdades sociais e econômicas, e as bases sociais do auto-respeito.” (RAWLS, 2000, p. 277-278)

Esses elementos essenciais formariam o que Rawls (2000, p. 181)) denominou de elementos constitucionais essenciais. ${ }^{12}$ A questão que se impõe sobre tais elementos constitucionais é a efetividades dos princípios que norteiam as liberdades e direitos fundamentais, e os princípios voltados à justiça social e econômica. O problema estaria em efetivar a implementação de tais princípios e não as suas diferenças. Para o autor, a execução dos elementos essenciais de primeiro tipo, voltados aos direitos e liberdades

\footnotetext{
${ }^{12}$ Há de se ter presente, como o próprio autor destaca, que "a distinção entre os princípios que abarcam as liberdades básicas e aqueles que se aplicam às desigualdades sociais e econômicas não está em que os primeiros expressam valores políticos e os últimos não. Ambos expressam valores políticos. A diferença é que a estrutura básica da sociedade tem dois papéis coordenados: os princípios que abarcam as liberdades fundamentais especificam o primeiro papel; os princípios que abarcam as desigualdades sociais e econômicas especificam o segundo. No primeiro papel, essa estrutura especifica e garante os direitos e liberdades fundamentais e iguais dos cidadãos e institui procedimentos políticos justos. No segundo, cria as instituições de base da justiça social e econômica apropriadas aos cidadãos em sua condição de livres e iguais. O primeiro papel preocupa-se com a forma de aquisição do poder político e com os limites de seu exercício." (RAWLS, 2000 p. 279)
}

Rev. De Teorias Da Justiça, Da Decisão E Da Argumentação Jurídica| e-ISSN: 2525-9830| Goiânia| v. 5 | n. 1 | p. 1-16 | Jan/Jun. 2019 
fundamentais, teriam uma maior probabilidade de aceitação e efetividade. Já os que se referem às "oportunidades equitativas e o princípio da diferença," especificamente as desigualdades econômicas e sociais encontradas na sociedade, configuram uma maior complexidade, por, muitas vezes, exigirem a análise de valores não políticos, o que foge da proposta de justiça como equidade. À medida que, porém, a sociedade for estável e movida por um acordo de cooperação mútua entre indivíduos livres e iguais, a possibilidade de divergências na execução dos elementos constitucionais essenciais poderá ser amenizada, considerando a proposta de uma justiça igualitária e razoável.

O que a razão pública exige é que os cidadãos sejam capazes de explicar seu
voto uns aos outros em termos de um equilíbrio razoável de valores políticos
públicos, sendo reconhecido por todos que, evidentemente, a pluralidade de
doutrinas abrangentes razoáveis professadas pelos cidadãos é considerada por
eles como algo que proporciona uma base adicional e muitas vezes
transcendente a esses valores. Em cada caso, a doutrina que cada qual professa
é uma questão de consciência para o cidadão individual. É verdade que o
equilíbrio de valores políticos de um cidadão deve ser razoável, e um equilíbrio
que possa ser considerado razoável pelos outros cidadãos; mas nem todos os
equilíbrios razoáveis são iguais. As únicas doutrinas abrangentes que entram
em choque com a razão pública são aquelas que não têm condições de sustentar
um equilíbrio razoável de valores políticos. (RAWLS, 2000, p. 294)

Nesse contexto, podemos afirmar que é a concepção política de justiça que dá o tom da razão pública e dos valores políticos que nela estão inseridos e que norteiam a ideia de justiça presente nas próprias relações entre os cidadãos de uma sociedade democrática. Qualquer argumento que possa emergir de doutrinas morais abrangentes e que não seja considerado razoável, poderia ser entendido como uma afronta ou injustiça diante dos valores políticos que se está a evidenciar. A razoabilidade da concepção de justiça que se está a defender, quando essa emerge do interior de uma doutrina moral, é fundamental para a harmonia e o consenso entre os cidadãos. A razão pública busca isso o tempo todo a fim de que o não razoável seja superado e substituído por argumentos passíveis de acordo.

Quando Rawls (2000, p. 299), expõe os limites da razão pública, ele faz menção a duas visões possíveis na relação da razão pública e as doutrinas morais abrangentes e seus argumentos; é o que ele denomina de "visão exclusiva" e "visão inclusiva". Compreende o autor que não haveria objeções quanto a uma doutrina moral abrangente apresentar suas posições relativas às questões políticas, restando saber, no entanto, se essas posições seriam objeto de acordo ou se estariam tão somente dando voz a uma 
doutrina moral abrangente. É o que ele chama de "visão exclusiva", ou seja, a própria doutrina ganharia destaque e colocaria na discussão pública as suas razões. A denominada "visão inclusiva", por outro lado, mostra que valores políticos enraizados em determinada doutrina moral abrangente poderiam ser trazidos para o fórum público e ser objeto de consenso, compondo o ideal da própria razão pública, sempre tendo presente o caráter razoável dessa proposição. A partir disso, “a visão inclusiva parece ser a melhor [...], admite essa variação e é mais flexível, quando isso é necessário para promover o ideal de razão pública."

Pensando com o autor americano, muitas vezes ao fazermos esse exercício de inclusão dos valores políticos enraizados em uma doutrina moral abrangente, estamos abrindo caminho para a reflexão sobre os ideais da razão pública, e não sendo contra ou subvertendo sua lógica. Seria uma espécie de força motora para a efetivação da razão pública propriamente dita. Para exemplificar Rawls (2000, p. 302-303) faz referência à luta abolicionista nos EUA desde 1830. Segundo o autor, "os abolicionistas poderiam dizer, por exemplo, que apoiavam os valores políticos da liberdade e da igualdade para todos [...]", no entanto, diante de tantas doutrinas abrangentes dominando o cenário da época “[...] era necessário invocar as razões abrangentes nas quais uma grande maioria acreditava que aqueles valores estivessem baseados."

Destaca Rawls (2000, p. 304-305), que:

\begin{abstract}
O ideal também, expressa uma disposição de ouvir o que outros têm a dizer e de aceitar acomodações ou alterações razoáveis na própria visão. A razão pública também exige de nós que o equilíbrio de valores públicos que consideramos ser razoável num caso específico seja um equilíbrio que julgamos sinceramente que os demais também considerem razoável. Ou, se isso não for possível, que pensemos que o equilíbrio pelo menos possa ser visto como não sendo algo desarrazoado [...] Isso preserva os vínculos da amizade cívica e é coerente com o dever da civilidade.
\end{abstract}

Nesse sentido, é fundamental um apoio mútuo entre a concepção política de justiça e o ideal de razão pública, o que dará sustentação para uma democracia constitucional, permeada, no seu interior, pelas mais variadas doutrinas morais abrangentes. Esse ideal de razão pública somente será possível quando todos os cidadãos (sempre considerando a concepção normativa de pessoa) endossarem valores políticos que estão de acordo com a proposta de justiça política possível em uma sociedade bem ordenada. 
É essencial que todo e qualquer assunto político esteja de acordo com os elementos constitucionais fundamentais, elementos esses que são oriundos da base principiológica. É necessário um equilíbrio razoável entre as doutrinas morais abrangentes no que diz respeito aos valores políticos por elas aceitos, por mais que em alguns momentos possa haver discordância entre tais doutrinas e a razão pública, esse descompasso deve ser mínimo, de maneira a prevalecer o interesse político/público.

Assim, há de se verificar se a discordância entre a doutrina moral abrangente e a razão pública viola os "elementos constitucionais fundamentais e as questões de justiça básica," posto que há um interesse em preservar os valores políticos que viabilizam o que Rawls denomina de liberalismo político. (RAWLS, 2000, p. 306)

A noção de razão pública vai emergir no contexto da teoria rawlsiana de justiça como equidade em dois momentos distintos. Primeiro, quando da proposta de razão pública para o interior das sociedades, e segundo, na obra O Direito dos Povos. Ambas as propostas não possuem o mesmo conteúdo, como o próprio autor especifica em diversas passagens do seu projeto, porém a essência da proposta seria a mesma quando se está a projetar os alicerces para uma cultura de fundo capaz de unir os indivíduos em torno de objetivos comuns. "Uma sociedade bem ordenada, pública e efetivamente regulada por uma concepção política reconhecida, cria um clima no qual seus cidadãos adquirem um senso de justiça que os inclina a cumprir seu dever de civilidade [...]" (RAWLS, 2000, p. 303)

\section{CONCLUSÃO}

O presente artigo buscou delinear os principais elementos apresentados por Rawls para a sua concepção de justiça para sociedades nacionais, o que consiste em uma concepção política (pública) de justiça e requer seja independente de qualquer doutrina moral abrangente, filosófica ou religiosa.

Esta concepção pública de justiça empregada pelo autor para desenvolver sua própria "teoria da justiça" denominada de "justiça como equidade", seria aquela apropriada para uma democracia constitucional, e que deverá ter como princípio basilar a tolerância.

Rev. De Teorias Da Justiça, Da Decisão E Da Argumentação Jurídica | e-ISSN: 2525-9830| Goiânia| v. 5 | n. 1 | 
Garantir as bases para a estabilidade e o consenso nas sociedades nacionais, bem como a relevância da estrutura básica, enquanto objeto primário da justiça, para pensar um projeto de justiça social que tem por base instituições sociais justas definidoras dos direitos e deveres fundamentais que norteiam os projetos de vida dos cidadãos, aparecem como prioridade no projeto de justiça política rawlsiana.

Nesse contexto, o estudo procurou compreender qual o papel desempenhado pela filosofia política e por que o conceito de justiça rawlsiano é político e se afasta de uma concepção metafísica. Ainda, analisou como referida concepção e algumas das suas questões fundamentais foram desenvolvidas na obra de 1971, A Theory, e tornaram-se mais claras a partir de escritos posteriores.

O próprio autor reconhece que não foi tão objetivo quanto deveria ter sido nas suas primeiras formulações e que as críticas colaboraram para posteriores elucidações, possibilitando um amadurecimento com relação a determinados conceitos. Talvez Rawls não tenha dado a ênfase necessária para sua proposta de pretender que a justiça como equidade fosse reconhecida como uma concepção política de justiça e isso, por vezes, proporcionou interpretações equivocadas e julgamentos inconsistentes.

A concepção política de justiça amplia a ideia de cidadania e busca a realização plena dos direitos e liberdades. Para Forst (2010, p. 272-273), “a cidadania é um conceito complexo, pois tem de abranger igualmente diferenças étnico-culturais, igualdade jurídica e características políticas comuns." Envolve o reconhecimento, por parte dos cidadãos, da sua igualdade e, também, do que os diferencia. Em termos de igualdade, o referido autor destaca a "igualdade como pessoas éticas, como pessoas de direito e como concidadãos", requisitos para serem considerados "membros plenos da comunidade política."

Com Forst (2010, p. 272-273) é possível analisar como Rawls trabalha essa ideia de cidadania plena, considerando a sua proposta de justiça social. A participação na sociedade, como cidadão, deve ser entendida como o núcleo rígido da teoria de justiça social em Rawls. Ou seja, o princípio da cidadania embasaria a proposta rawlsiana de justiça social, fundada no respeitomútuo entre seus membros mesmo em uma sociedade plural, composta por várias concepções de bem. Por tal razão, Forst reafirma que não é possível esquecermos que a teoria de justiça social, proposta por Rawls, está justificada pela ideia de posição original e pelo conceito de pessoa (ideal de pessoa). Isso 
corresponderia "a um ideal de cooperação social entre tais pessoas que possuem concepções de bem incompatíveis e um senso comum para a justiça."

A cooperação social, presente na teoria de justiça como equidade, exige dos cidadãos um auxílio mútuo, ou seja, que queiram cooperar uns com os outros no sentido de construir uma sociedade cooperativa. Para que isso efetivamente aconteça, é necessário que os indivíduos envolvidos, na qualidade de cidadãos livres e iguais, compreendam o quanto fundamental é a sua participação e colaboração para que a justiça como equidade se concretize como projeto de justiça social. A noção de pessoa que envolve uma concepção política, não metafísica nem psicológica, é uma formulação compatível com a própria ideia de justiça presente em uma sociedade democrática.

Para tanto, como forma de conclusão do presente artigo, necessário se faz retomar a noção de razão pública. A argumentação rawlsiana em torno do conteúdo da razão pública deixa claro a sua importância na construção de uma sociedade justa e igualitária. A razão pública irá se estabelecer tendo como base uma concepção de justiça política aplicada ao que Rawls denominou como estrutura básica da sociedade, formada por suas principais instituições políticas, sociais e econômicas. É a partir desse contexto que seria possível articular um sistema de cooperação que independe de doutrinas morais abrangentes, mas que considera relevantes as ideias políticas e públicas presentes de forma implícita na cultura democrática de fundo, base da sociedade. Tais ideias criariam as diretrizes para o estabelecimento dos valores que irão permear a construção dos elementos constitucionais fundamentais e por fim, a razão pública de uma sociedade democrática.

\section{REFERÊNCIAS}

AUDARD, Catherine. Cidadania e democracia deliberativa. Tradução de Walter Valdevino. Porto Alegre: EDIPUCRS, 2006.

BOYER, Alain. Justiça e Igualdade. In: BOYER, Alain; KERVÉGAN, Jean-François; JAFFRO, Laurent; PÉCHARMAN, Martine. Ensaios de Filosofia Política. Tradução de Fulvia Moretto. São Leopoldo: Editora UNISINOS, 2001.

COHEN, Joshua. Democracy and Liberty. In: ELSTER, J. (ed.) Deliberative Democracy. Cambridge: Cambridge University Press, 1998.

FORST, Rainer. Contextos de Justiça: filosofia política para além de liberalismo e comunitarismo. Tradução de Denilson Luís Werle. São Paulo: Boitempo, 2010. 
LOVETT, Frank. Uma teoria da justiça de John Rawls. Guia de leitura. Tradução de Vinícius Figueira. Porto Alegre: Penso, 2013.

RAWLS, John. A Theory of Justice. Revised Edition. Cambridge, Massachusetts: Harvard University Press, 1999.

RAWLS, John. Uma Teoria da Justiça. Tradução de Almiro Pisetta e Lenita M. R. Esteves. São Paulo: Martins Fontes, 2002.

RAWLS, John. Justice as Fairness: Political not Metaphysical. In: Philosophy and Public Affairs, Vol.14, No.3. 1985. p. 223-251.

RAWLS, John. Justiça como equidade: uma concepção política, não metafísica. In: Lua Nova: Revista de Cultura e Política. n. 25. Tradução de Regis de Castro Andrade, 1992. p.. 25-59.

RAWLS, John. Justice as fairness: a restatement. Cambridge, Mass: Harvard University Press, 2001.

RAWLS, John. Political Liberalism. New York: Columbia University Press 1993.

RAWLS. John. O Liberalismo Político. Tradução de Dinah de Abreu Azevedo. 2. ed. São Paulo: Ática, 2000.

RAWLS, John. Conferências sobre a história da filosofia política. Organizado por Samuel Freeman. Tradução de Fábio M. Said. São Paulo: Marins Fontes, 2012.

RAWLS, John. The Law of Peoples; With the idea of Public Reason Revised. Second printing. Harvard University Press, 2000.

RICOEUR, Paul. O justo ou a essência da justiça. Tradução de Vasco Casimiro. Lisboa: Instituto Piaget, 1995. 